\title{
An Evaluation Of A Public Energy Loan Program: The Characteristics Influencing Inquiry And Participation By Firms
}

\author{
Ferdinand G. DiFurio, Tennessee Tech University, USA
} Ferdinand Vinuya, The World Bank

\begin{abstract}
Public programs designed to subsidize the use of energy conserving technologies are becoming widely used policy initiatives targeting both the public and private sector. Proponents of such initiatives point to its win-win nature of promoting energy conservation: it not only benefits the economy as a whole, but also allows private benefits to accrue to program participants. This paper attempts to identify the firm-level and regional characteristics that influence the likelihood of participation for firms in a public energy loan program. The results show that the loan amount requested by firms is inversely related to participation. Participation falls with proprietorships, partnerships, and corporations when compared with charitable associations, non-profits and government entities. Those companies benefiting the most from small changes in energy efficiency exhibit a significant increase in participation rates. Firms located in metropolitan areas are associated with increased participation when compared with their non-metropolitan counterparts. There is also evidence that program inquiries move with interest rates, suggesting that during periods of rising rates, companies may seek out the program's reduced interest rate to subsidize investment projects. Policymakers may use these findings to better understand how energyrelated issues apply to the profit-maximizing decision of the firm.
\end{abstract}

Keywords: energy policy, logistic regression, energy conservation, alternative fuels, public energy programs.

\section{INTRODUCTION}

¿ $\mathrm{n}$ an age of rising energy costs, firms will seek to minimize costs through various energy conservation methods. They weigh the costs and benefits associated with adopting an energy-saving technology, which may range from efforts to reduce carbon dioxide emissions to the use of solar equipment to run manufacturing processes. From a social perspective, government agencies, in an effort to possibly address a market failure in commercial energy conservation, use incentive programs to encourage public and private entities to make these changes. These can include corporate and personal tax credit programs, rebate programs and direct cash-back promotions, and low-interest loan programs (Gouchoe, et. al). However, in order for these incentives to be effective, they must be adequate to make the benefits exceed the costs of adoption by firms. As this paper shows, the services offered by these programs are often offset by what the market provides. A firm's unwillingness to participate is a signal that a public program is not addressing their business wants, implying that the private market should not be overlooked as a sufficient mechanism to improve energy conservation.

This paper uses descriptive statistics along with a logistic regression to 1) analyze how inquiries by firms into the program vary over time and by regional classification, and 2) measure the influence of firm-level and regional characteristics on the likelihood of participation in a government-sponsored energy initiative. Tennessee's Small Business Energy Loan Program will serve as the case study. From a policy standpoint, this information can be used to improve participation rates in the program by identifying characteristics most strongly associated with joining. In addition, digging deeper into the firm's cost-benefit decision would help to better understand those factors playing the largest role in participation an era of heightened energy awareness. The government initiative 
itself may be called into question. Is the program best suited to serve some industries and not others, and is the program really addressing a market failure in commercial energy use? Ultimately, social optimums will become increasingly critical as the global community addresses the external cost element associated with industrial production. Knowing more about how firms behave in energy-dependent markets will add value to economic policy in the long run. The goal of this paper is to look historically at a single public program devoted towards energy conservation in order to gain insight on how industries, along with how agencies tasked to execute the program, are behaving.

\subsection{Energy Program Backround}

The U.S. Energy Information Administration projects an annual growth in gross domestic product from 2005 to 2030 of $2.9 \%$ (EIA, 2007). This is an adjustment downward from a previous estimate primarily due to rising energy prices inhibiting faster growth. Along with a changing public sentiment towards energy use, energy prices, economic growth, and technological progress will influence trends in energy consumption far into the future. New regulations push for alternative energies to offset reliance on traditional fossil fuels. The AEO predicts both an increased consumption of renewable biofuels along with growth in areas such as new transportation innovations and nuclear power capacity. ${ }^{\mathrm{i}}$ With all of these changes taking place, the global market will be affected in many ways, ultimately influencing statewide energy policies. Public programs will offer many incentives to curb energy use, but they should be effective in offering the right incentives, and may benefit most by incorporating the best use of private markets.

The state of Tennessee ranked 14th in the nation in 2003 for residential energy consumption (507.6 trillion BTUs) and 15th and 12th for commercial sector (373.9 trillion BTUs) and industrial sector (761.7 trillion BTUs) consumption, respectively (DOE). In 2006, commercial and industrial electricity prices in Tennessee were both approximately $89 \%$ of the U.S. average (expressed in cents per kilowatt hours), and total net electricity generation for TN was $2.4 \%$ of the U.S. ${ }^{\text {ii }}$ Energy conservation in the state is well recognized as a primary public agenda through a myriad of laws, regulations and energy programs. This aggressive energy stance might be expected as Tennessee encourages small business growth and industry development, which are often linked with undesirable environmental effects. For instance, some laws such as the Liquefied Petroleum Gas (LPG) Liability Immunity work to protect private businesses from civil liabilities involving LPG transactions (DOE). On the other hand, regulations on biofuels to promote the use of renewable energy may impact adversely an otherwise efficient production process of a manufacturing plant. In addition, there are many statewide programs dedicated towards energy conservation. Some of these include the Tennessee Energy Education Network, Industries of the Future, Grants Management Program and Energy Emergency Planning.

Since 1988, the Small Business Energy Loan Program within the Tennessee Department of Economic and Community Development has been operating with the goal of improving energy efficiency for small companies (less than 300 employees or 3.5 million in annual gross sales or receipts). By offering low-interest to zero-interest loans up to $\$ 300,000$ for a maximum term of 7 years, this program gives the business owner the opportunity to make energy-efficient changes at a low-cost to improve overall operations. More specifically, the loan program helps the small firm identify (through free energy audits), purchase and install approved energy efficiency measures. Such efficiency measures might include one or some combination of the following: insulation improvements, doublepane window installation, heating and cooling changes and lighting improvements.

Firms will decide to adopt an energy-saving technology if it is consistent with its profit-maximizing objective. Therefore, a firm will approach these incentive programs in much the same way they evaluate any project undertaking: by weighing the discounted present value of the benefits to the costs of the project. From an empirical standpoint, research that measures the characteristics that affect adoption of an energy-saving technology basically points to this benefit-cost decision. Programs that succeed in offering private firms energy-saving technologies should be efficient in their delivery. It follows that firms must also be willing and able to successfully implement the energy changes. Ultimately, identification of those firms most likely to do these programs would provide agency administrators with information regarding where their resources are most valued. 


\subsection{Factors Influencing Participation}

The literature on technology adoption is rich, and many factors do work to encourage and discourage the implementation of a technology. DeCanio and Watkins (1998) remark that economic theory purports firms will adopt an energy-saving technology if the investment has a positive net present value. The authors use a discrete choice regression to determine whether firm characteristics play a role in the decision to participate in a voluntary EPA program. iii Their results support the notion that firm characteristics, such as firm size, financial health, industry-type, and EPA regional classification influence the choice to join the program. For instance, firms with a lower cost of capital were found to have an increased participation rate into the program. Also, relative to manufacturing sector firms, those firms in the finance, insurance, real estate, and service sectors were linked to lower rates of participation. Canadian firms surveyed in a study by Baldwin and Lin (2001) reported that the traditional costs associated with starting a new technology, such as end-user learning curves and support technologies, influence the decision for not adopting. de Groot et al. (2001) identify the factors associated with energy saving investment decisions by surveying a group of Dutch firms. They conclude that the desire to save on costs encourages such investments, however, competing, non-energy saving projects along with the high expenses associated with implementing the technology work against the decision to adopt. Pizer et al. (2002) look at the role of plant characteristics on the decision to adopt new energy-saving technologies. Their findings show that an improved financial health and higher energy prices were associated with increased levels of adoption. The debate continues regarding whether public programs designed to curb energy use among private firms are effective. Lancaster and Berndt (1984) find a mixed collection of results when examining how different state incentives along with other variables influence residential demand for solar technologies. Income tax credits, along with rising gas prices increase the demand for residential solar units. However, property tax breaks, lower solar prices, and higher electric costs did not seem to significantly influence the number of solar units demanded. Loan programs used by states to incent installation of solar equipment could not be effectively measured. Although this analysis was residential, it shows how varied state incentive plans can be in their effectiveness.

Verhoef and Nijkamp (2003) discuss how energy use impacts the profitability of firms, and find that the use of subsidies to incent firms to adopt a new energy technology can have unintended results. For instance, a subsidy may encourage both an adoption of the technology and an increase in production level, which may skew the effectiveness of the energy policy (p. 22). However, Carraro and Siniscalco (1992) argue that subsidies surpass other incentive vehicles in promoting effective energy use change. Gielecki et al. (2001) report that investment tax credits to promote commercial innovation in renewable energy such as solar and wind have had minimal effects. Overall, financial incentives designed by Federal and State governments continue to be an active tool in promoting the use of renewable energy sources and improve energy conservation. In the following section, the methodology used in this paper is discussed along with a description of the variables used in the logistic regression model.

\section{METHODOLOGY}

This paper attempts to identify the characteristics, both firm-level and regional, that are most strongly connected with inquiry and participation in a Small Business Energy Loan Program. ${ }^{\text {iv }}$ This paper contributes to the existing body of work in the following ways: First, regional characteristics are examined to test for the influence of location on the pattern of inquiries and participation. Second, the data set is unique in its ability to measure how firm-level variables such as "organization type" and "project use for the loan" are connecting with the likelihood of participation.

The approach towards evaluating the Small Business Energy Loan Program and its policy implications will take the following direction: First, inquiries into the program will be examined over the period to investigate how economic indicators, such as the market interest rate, may have influenced the program's activity. Inquiries will also be tabulated by regional classification (metropolitan versus non-metropolitan) to investigate whether geography played a role in the pattern of firm inquiry. Second, an examination of how participation is linked with firm-level and regional characteristics will be conducted. It is important to point out that participation into the program goes beyond the initial inquiry on the part of the firm, as it includes both a willingness (as demonstrated by the inquiry) and ability (as demonstrated by an approval and successful completion) to do the loan program. 


\subsection{Inquiry}

To prepare the data, the county of each firm inquiring is defined as metropolitan or non-metropolitan. Since the data series is time-oriented, classifying a firm as operating in metro or non-metro county while accounting for time of inquiry, poses a problem. For instance, a firm inquiring with the program in 1988 may have been operating in a county classified as rural, but that county may have grown into a metropolitan center by 2001, thus, changing its classification for inquiring firms later in time. Also, the Economic Research Service provides rural urban continuum codes that classify counties according to their regional classification. The classifications were done in 1993 and in 2003, so firms inquiring throughout this period may be sensitive to changes in a county's rural urban classification.

A total of 67 counties were represented by the 373 firms inquiring with the program from 1988 to 2006. ${ }^{\vee}$ Of the 67 counties, 8 (Sequatchie, Hamblen, Chester, Bradley, Hickman, Jefferson, Smith, and Cannon) experienced a change in their classification from non-metro to metro over the study period, while 1 (Sevier) county went from metro to non-metro. ${ }^{\mathrm{vi}}$ The choice was made to use the 2003 rural urban continuum codes to classify counties by regional definition. This decision is based on 1) the small number ( 8 counties) that changed definition over the study period 1988 to 2006, and 2) preliminary testing revealed no significant difference in outcomes when using the 1993 codes versus the 2003 codes.

\section{$2.2 \quad$ Logistic Regression}

Logistic regression is used to estimate the odds of participation in the loan program by a business. Therefore, the dichotomous dependent variable Result is equal to 1 if the firm is approved (232 observations) and successfully completes the program and equal to 0 if otherwise (123).

Id The variable Id attempts to control for the firm's time of inquiry with the Small Business Energy Loan Program. This time trend is included to control for the association between the time of inquiry and likelihood of participation. For example, was there a significant difference in the program's effectiveness, in terms of participation, on firm's applying later in the loan program's lifetime?

Amount The variable Amount is a quantitative variable that is the amount of funds requested (expressed in thousands) at the time of application. The sign on this variable is hard to predict. On one hand, firms requesting larger amounts (albeit within the maximum amount requested allowable by the program) may signal to the program a questionable state of financial health, leading to lower likelihoods of participating. However, this motive might not be clear if the agency is strict about where the money should be spent. On the other hand, there is the possibility that larger amounts requested are associated with stronger intentions to improve energy efficiency, leading to higher likelihoods of participation.

Type In order to examine how the likelihood of participation changes with the type of firm, a variable entitled Type was included in the model. Type is a categorical variable with 4 levels that classifies each firm (defined by the Department of Economic and Community Development's Energy Division) as one of the following: 1=corporation, 2=partnership, $3=$ proprietorship, $4=$ other.

Sector The categorical variable Sector looks at how the likelihood of participation might vary according to the firm's target sector for the technological change using the program's funds. There are 7 levels for the variable Sector, and the definitions are as follows: 1=manufacturing/processing/assembling, 2=wholesaling or retailing, $3=$ groceries, markets, restaurants and food service, 5=property management, lodging/housing related and office space for lease, $6=$ medical services and veterinarian services, $10=$ educational, religious and others not classified, and $12=$ dry cleaners, launderers and general services (banking, real estate, legal). These definitions can be found in the Appendix.

Project The variable Project is a categorical variable that measures the specific type of energy-efficiency change being taken using the loan program. The goal is to determine how the likelihood of participation varies according to 
the specific energy change requested. There are 3 levels of this variable and they are as follows (the entire list of definitions can be found in the Appendix): When Project=1, this category includes a group of firms making changes in heating and cooling ventilation systems and other related energy management systems. When Project $=2$, this category includes a group of firms making utility plant and distribution system modifications or water heating type changes. ${ }^{\text {vii }}$ When Project $=3$ (the omitted, or base category) this category includes a mixed group of firms making changes ranging from caulking, weatherstripping, and insulation to solar and renewables.

It is important to point out that the categories for the variable Project are not entirely mutually exclusive. For instance, Project=3 includes firms that may have changes consistent with changes in either category 1 or category 2. Entire separation of these categories is difficult due to the lack of specific firm-level data. Despite these deficiencies, categories 1 and 2 are viewed as different from 3 so that comparisons can be made on how participation varies across these groups.

\section{Metro}

The variable Metro is equal to 1 if the firm operates in a metropolitan county (those rural-urban continuum codes equal to 1,2, or 3 ) and equal to 0 if otherwise. When Metro equals 0 , this group contains firms operating in a non-metropolitan county adjacent to a metropolitan area (those rural-urban continuum codes equal to 4,6 , or 8 ) and also firms operating in a non-metropolitn county nonadjacent to a metropolitan area (those rural-urban continuum codes equal to 5,7 , or 9 ).

\subsection{Model}

Model

$\log \left[\frac{P_{i t}}{1-P_{i t}}\right]=\alpha+\beta_{1} \mathrm{Id}_{\mathrm{it}}+\beta_{2}$ Amount $_{\mathrm{it}}+\beta_{3}$ Type $_{\mathrm{it}}+\beta_{4}$ Sector $_{\mathrm{it}}+\beta_{5}$ Project $_{\mathrm{it}}+\beta_{6}$ Metro $_{\mathrm{it}}+\varepsilon_{\mathrm{it}}$ where $\mathrm{i}=$ the $\mathrm{i}^{\text {th }}$ firm of inquiry and $\mathrm{t}=$ the time of inquiry, $\boldsymbol{P}_{i t}=$ probability that Result ${ }_{\mathrm{it}}$ is equal to 1 , Id is a time trend that rises consecutively with the inquiry, Amount is a quantitative variable equal to the loan amount requested (in thousands) at the time of inquiry, Type is a class variable that is equal to 1 if the $i^{\text {th }}$ firm is a corporation, 2 if partnership, 3 if proprietorship, and 4 if other, Sector is a class variable that designates what sector of production the $i^{\text {th }}$ firm in time $t$ will use the energy loan for, Project is a class variable that varies according to the specific energy change being made, Metro is a dummy variable that is equal to 1 if the firm operated in a county classified as metropolitan in 2003 , and 0 if otherwise.

\section{$3 \quad$ RESULTS}

\subsection{Status Outcomes}

The data set for this research was provided by the state of Tennessee's Department of Economic and Community Development, Energy Division. There were 373 total businesses establishing inquiries through a loan application with the Small Business Energy Loan Program from 1988 to 2006 . Of the 373 total businesses inquiring, 18 that were defined as either "approved, but not completed" or "pending" were removed due to their indeterminate nature. The remaining 355 observations were defined: 23 as "administrative rejection," 26 had "voluntary withdrawal," 16 were "financial rejection," 46 were "never heard from" after the initial application, 232 had "successful completion," and 12 had "default or written off" (Table 1). 
Table 1: Status of Loan Applications

\begin{tabular}{lcc}
\hline \multicolumn{1}{c}{ Status } & Frequency & Percent \\
\hline "administrative rejection," & 23 & 6.48 \\
\hline "voluntary withdrawal," & 26 & 7.32 \\
\hline "financial rejection," & 16 & 4.51 \\
\hline "never heard from" & 46 & 12.96 \\
\hline "successful completion," & 232 & 65.35 \\
\hline "default or written off" & 12 & 3.38 \\
\hline Total & 355 & 100.00
\end{tabular}

\subsection{Inquiries}

Figure 1 plots the number of firms inquiring in each year from 1988 to 2006. The trend line shows that inquiries into the program peaked in 1992 and then steadily fell. The program coordinators attribute the spike in 1992 to an Environmental Protection Agency (EPA) regulation requiring dry-cleaner businesses to improve the management of their "closed systems." This meant that these businesses had to recycle waste, and inquired with the state's energy program to investigate ways to offset this effective increase in transition costs.

The steady decline of inquiries might be explained by national trends in electricity prices. The Department of Energy reports that all sectors, including residential, commercial, and industrial were paying lower rates for electricity (as measured in chained cents per kilowatt hour) in 2005 as compared with $1960{ }^{\text {viii }}$ In addition, the decline in inquiries might be attributed to several other factors, some of which might include 1) the recession of 2001 , 2) the mechanisms of the market providing sufficient avenues for companies to address energy, 3) a slow saturation of those firms willing and able to participate during this period, and 4) a general, downward trend in interest rates over the period of the program.

Figure 1: Number of Firms Inquiring about the Program, 1988-2006

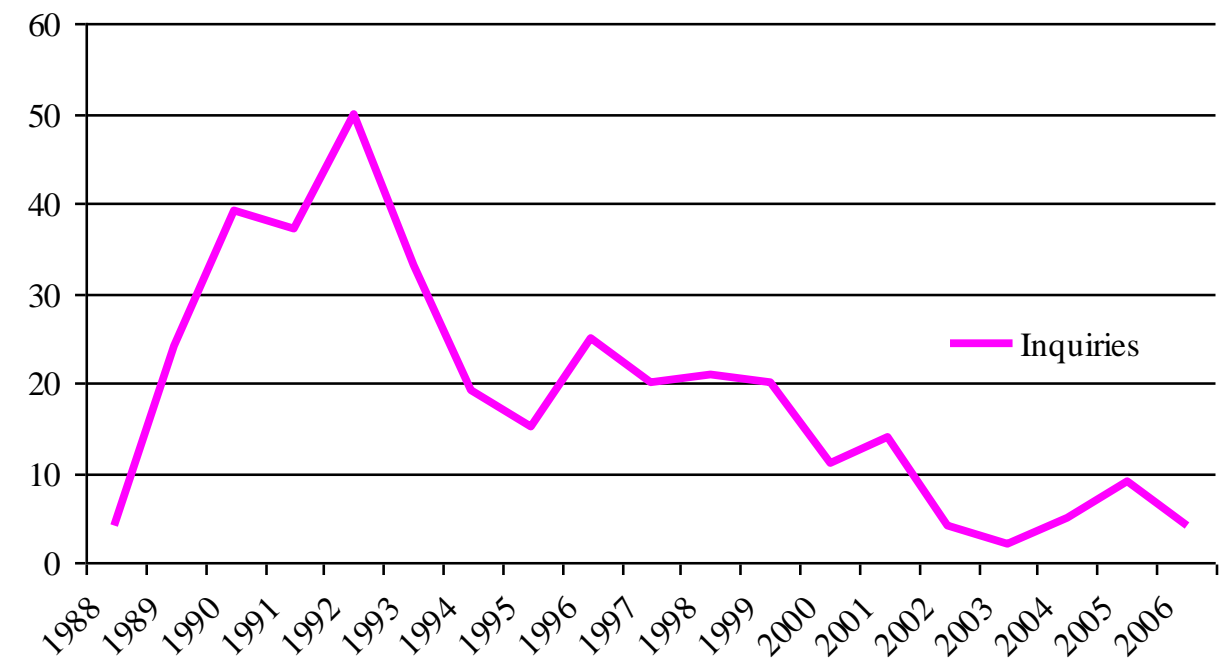

The monthly, short-term Federal Funds rate was used to test for an association between inquiries and the market interest rate. For the marginal firm, the substantially reduced energy loan program rate may have been a competitive alternative to a market-driven, energy project within some specified range of interest rates. A positive correlation coefficient of $0.26156(\mathrm{p}=0.0001)$ was obtained for monthly inquiries (beginning in 1988) and the 
monthly, short-term Federal Funds interest rate, indicating that program inquiries were moving with interest rates to some extent. Figure 2 supports this finding, as the number of monthly inquiries (when "smoothed" with a polynomial function) seem to follow monthly interest rates. Although no causal relationship can be directly implied here, there is evidence to suggest that companies may have seeked out the program for the reduced-interest rate, thereby effectively subsidizing their costs of borrowing.

Figure 2: Interest rate and number of inquiries

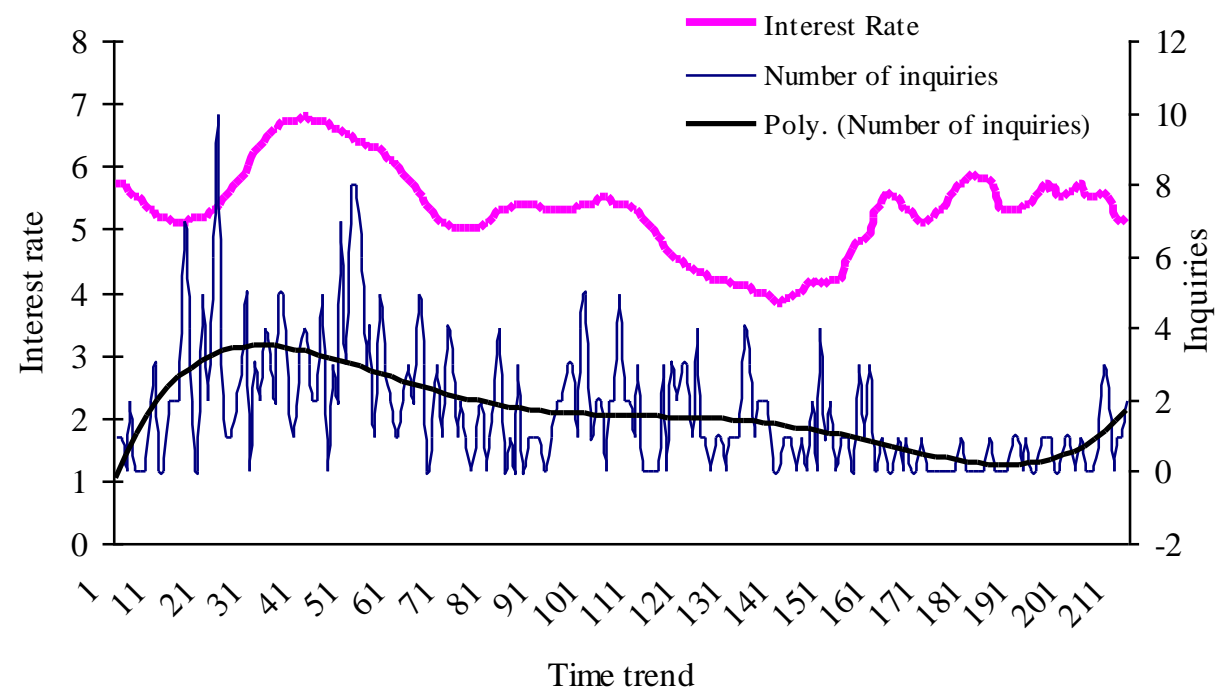

The regional analysis, as it pertains to inquiries, is discussed in this next section.

Figure 3 maps inquiries from 1988 to 2006 by county for the state of Tennessee. As expected, those counties with the most inquiries (between 38-67 inquiries) with the program are metropolitan (Knox, Davidson, and Shelby). Overall, there does appear to be a pattern with inquiries by county. Those non-metropolitan counties with relatively high inquiry counts (between 5-8 and 3-4) cluster around the highest count metropolitan counties. Next, Figure 4 shows the map for inquiries by regional definition of the county (metro versus non-metro). ${ }^{1}$ The map highlights only those counties that are metro by including a caption entitled "Metro" (the figure immediately below its caption represents the number of inquiries). It is clear from the map that several metro counties do have most of the highest inquiry counts (orange $=4$ counties and red $=3$ counties), but metro counties also account for several of the low, inquiry counts (opaque white $=3$ counties, light gray $=4$ counties, dark gray $=3$, and yellow $=5$ counties). These results suggest that the inherently larger sample pool of businesses in a metro area might not be sole driving force inquiries into the program, as evidenced by the low inquiry counts for several metro counties.

\footnotetext{
${ }^{1}$ These definitions are provided by the 1993 rural urban continuum codes, Economic Research Service.
} 
Figure 3

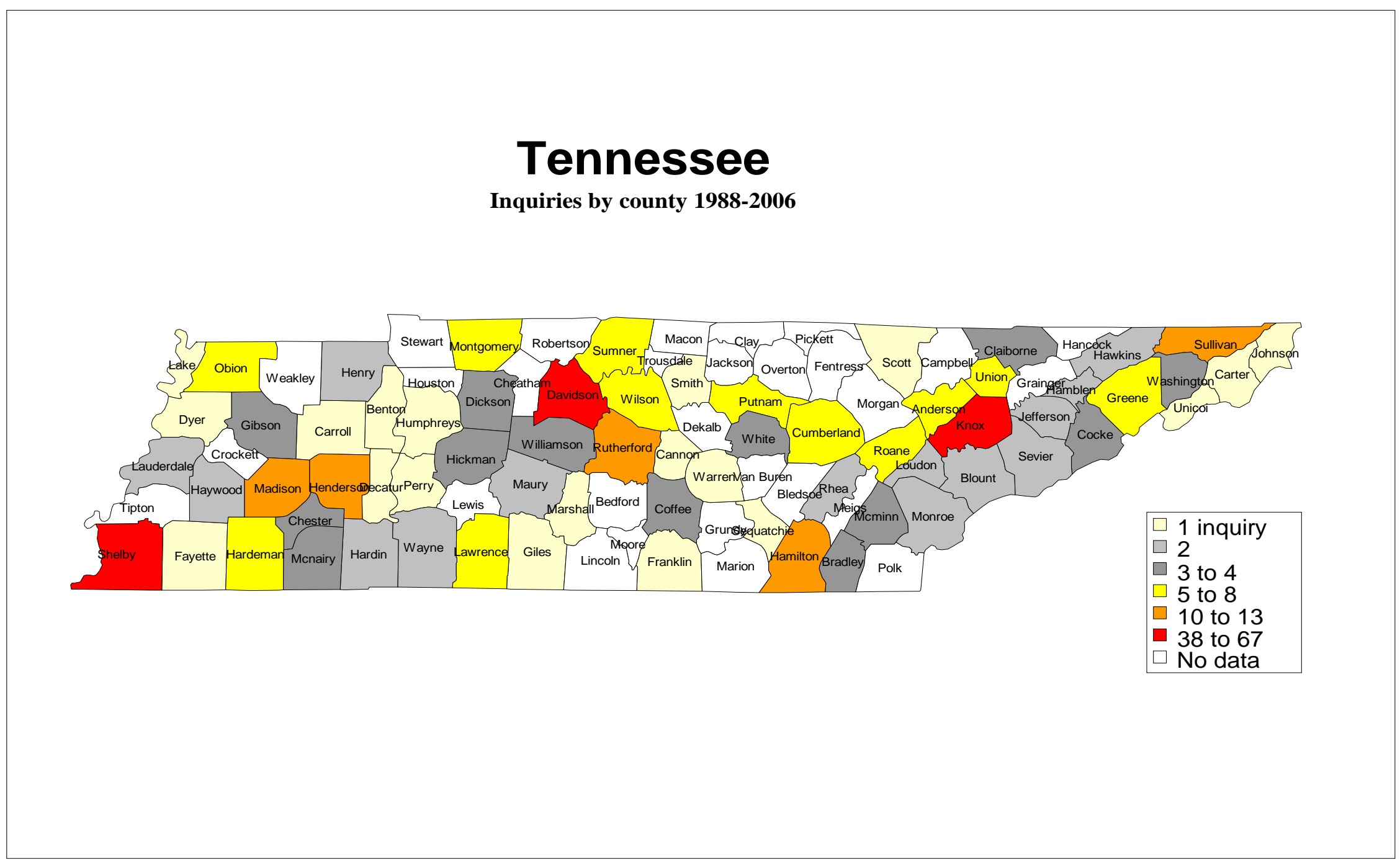


Figure 4

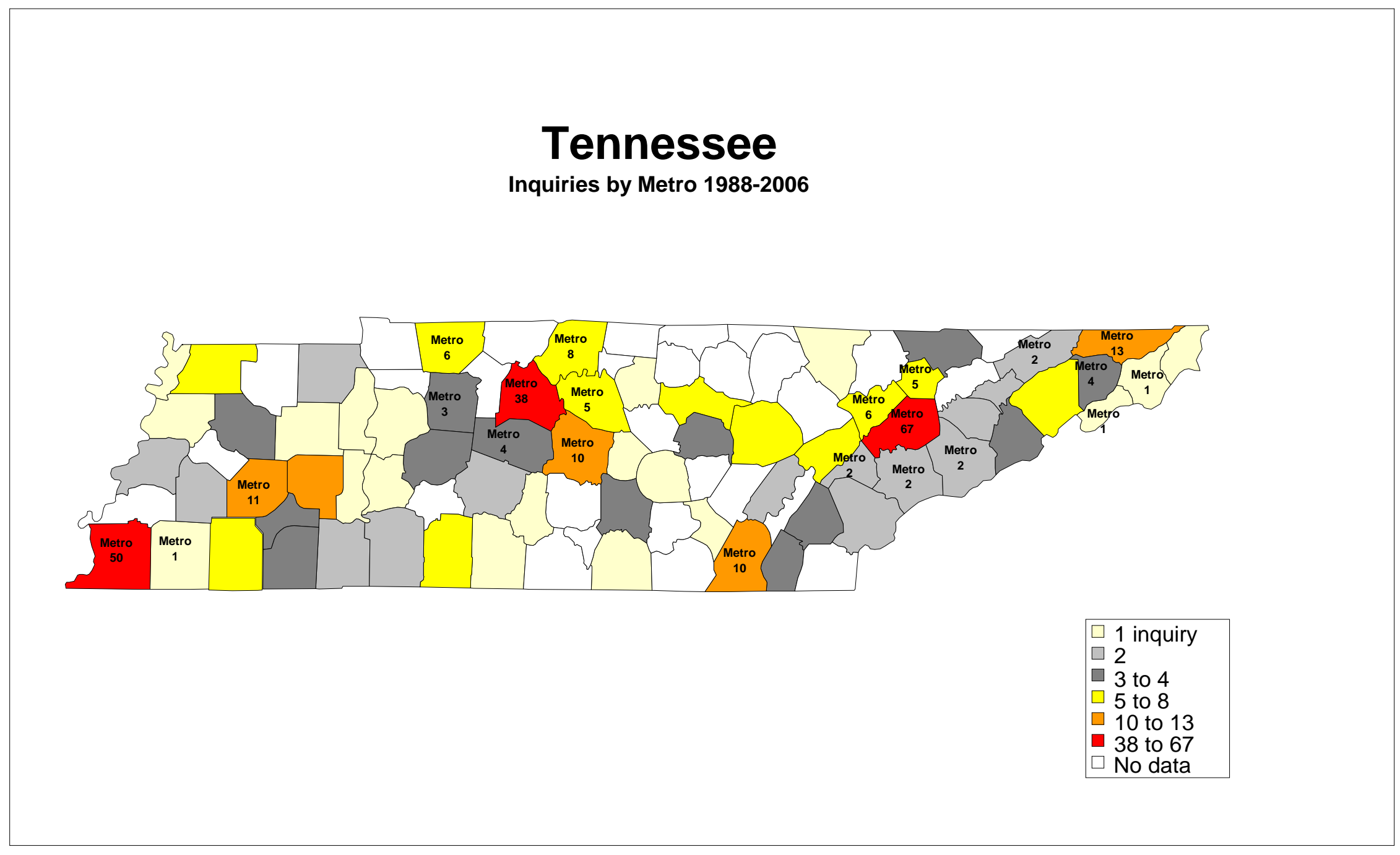




\subsection{Participation}

Figure 5 shows how participation varies with time. Those companies that applied for the loan but did not participate due to the reasons explained in Table 1 are identified as non-participating (labeled nonpart), while the firms that applied and successfully completed the program are identified as participating (labeled part). ${ }^{2}$

Figure 5: Number of participants through time

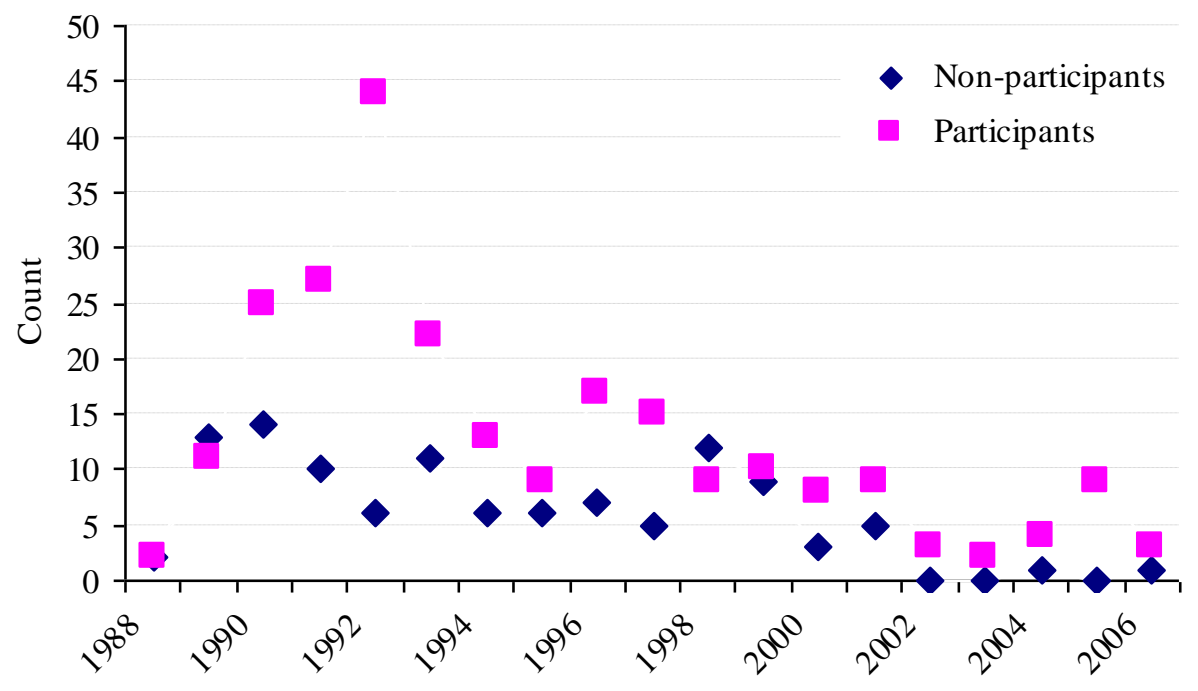

There appears to be a healthy share of firms inquiring and also participating (finishing the loan program) during the period roughly between 1990 and 1997. During the period, companies making "utility plant and distribution system" or "water heating" (when Project $=2$ ) are largely contributing to the high participation rate as all inquiring during this period completed the program (Table 2). There is another period of activity when the gap between non-participation and participation was closing, as between the years 1998 and 1999. Participation is lower during this period along with the existence of those firms making "utility plant and distribution system" or "water heating" changes (Table 3). There is a steady decline in the program inquiries after the year 1999 (Table 4). During this period, however, other energy changes, such as those made to "heating, ventilation and air conditioning $($ HVAC), etc." (Project $=1$ ) and other "energy or heat recovery modifications" (Project $=3$ ) were driving high participation rates. In summary, the high inquiries and participation rates between 1990 and 1997 were being mainly driven by select companies looking to make specific changes using the program. In the few years following, the gap was closing between non-participation and participation. In the remaining years after 1999, companies making other types of changes (in contrast with those made between 1990 and 1997) were accounting for the program's inquiries and participation.

\footnotetext{
${ }^{2}$ The year on the horizontal serves as only a signal to the firm's initial inquiry, as those firms participating may have completed the program many years later.
} 
Table 2: Participation Between 1990 and 1997

\begin{tabular}{llll}
\hline Outcome (RESULT) & \multicolumn{2}{l}{ Energy Change (PROJECT) } & PROJECT=3 (\%) \\
\hline & PROJECT=1 $(\%)$ & PROJECT=2 $(\%)$ & \\
\hline Non-Participants & & & $34(26)$ \\
\hline Participants & $31(33)$ & $0(0)$ & $97(74)$ \\
\hline Totals & $62(67)$ & $13(100)$ & 131
\end{tabular}

Table 3: Participation Between 1998 and 1999

\begin{tabular}{llll}
\hline Outcome (RESULT) & \multicolumn{2}{l}{ Energy Change (PROJECT) } & PROJECT=3 (\%) \\
\hline & PROJECT $=1(\%)$ & PROJECT=2 $(\%)$ & \\
\hline Non-Participants & & & $16(62)$ \\
\hline Participants & $5(38)$ & $0(0)$ & $10(38)$ \\
\hline Totals & $8(62)$ & $1(100)$ & 26
\end{tabular}

Table 4: Participation After 1999

\begin{tabular}{llll}
\hline Outcome (RESULT) & \multicolumn{2}{l}{ Energy Change (PROJECT) } & PROJECT=3 (\%) \\
\hline & PROJECT=1 $(\%)$ & PROJECT=2 $(\%)$ & \\
\hline Non-Participants & & & $9(24)$ \\
\hline Participants & $1(10)$ & $0(0)$ & $29(76)$ \\
\hline Totals & $9(90)$ & $0(0)$ & 38
\end{tabular}

Table 5 shows the status of the loan applications (as defined by Participated, labeled part, or Not Participated, labeled nonpart) by firms according to the regional status of the county they operated in. For the participating category (part), the share of Non-metro firms (26.72\%) is lower than the share of Metro firms (73.28), giving Metro firms an edge in participation. However, for the non-participating category (nonpart), Metro firms also share the edge in non-participation (65.85). This regional effect will be examined further in the logistic regression, as a variable is included in the model to test for a significance difference between the metro and non-metro groups.

Table 5: Status of Loan Applications

\begin{tabular}{llll}
\hline Region & part (column \%) & nonpart & Total \\
\hline Non-metro & $62(26.72 \%)$ & $42(34.15)$ & 104 \\
\hline Metro & $170(73.28)$ & $81(65.85)$ & 251 \\
\hline Total & 232 & 123 & 355
\end{tabular}

Logistic regression is used next to determine how the log-odds of participation vary with firm-level and regional characteristics. The results for the logistic model are presented in Table 6 entitled Model Results. Of the total 355 observations from Table 1, 343 were used in the logistic regression.

The reported coefficient for Amount is significant and negative, indicating that the odds of participation fall with the amount requested. The program administrators explained that some companies asking for relatively higher amounts were usually planning production changes on a very large scale. As a result, these firms would request the maximum amount, or some amount close to the maximum, as part of funding a larger project budget. However, it was noted by the program's administrators that they would often rescind their application and choose alternative methods of funding.

The reported coefficients on Type are all significant and negative in sign, indicating that participation falls with corporations, partnerships, and proprietorships. The baseline group (the omitted, or baseline category is Type $=4$, and the results should be interpreted as comparisons from this baseline category) includes associations 
(charitable, trade, or professional entities), city or county governments, educational non-profit groups, non-profits, religious institutions, etc. The outcome here points to slight differences in the decision to do the energy loan program. All institutions weigh the discounted net present value to the costs when making an investment decision, however, corporations, when compared with a not-for-profit might face lower thresholds for error when calculating to borrow. In other words, the discounted present value of the benefits from the program may not have exceeded the costs for the corporate types.

The variable Sector describes a target use for the energy change being made. Categories 1, 3, 5, and 10 are statistically significant (these categories should be interpreted as changes from the omitted category 12). The signs on each category are negative, implying that participation falls with these groups when compared with the base category. Without resorting to explaining each group in detail, a more useful approach is to examine the make-up of the base group.

The base group, or category 12 , contains a group of firms operating in the dry cleaning industry. These firms were experiencing higher rates of participation (along with higher inquiries) during the 1992 period resulting from an EPA regulation (discussed earlier in the section entitled Inquiries). This may help to partially explain the dramatic drop in participation for those groups outside of this base category.

The coefficient on the variable Project for category 2 is significant. This shows that participation rises for those firms making changes in either "utility plant and distribution systems or water heating" (as compared with the baseline category, Project=3). The program administrators describe these companies as those realizing large returns from small changes, suggesting that this group might view the program as a rewarding prospect. From the perspective of the program, this result may also reflect the program administrator's goals to approve firms making energy changes with a greater energy-savings impact.

The regional effect coefficient is reporting significance at the $10 \%$ level. There is some evidence to suggest that the log-odds of participation rise with metropolitan firms (when compared with the base group of nonmetropolitan firms). Specifically, the log-odds of participation rise by $10.48 \%$ for metropolitan firms. ${ }^{\text {ix }}$ This result is consistent with the descriptive data presented in Table 5, where metropolitan firms held a slight edge in participation.

Table 6: Model Results

\begin{tabular}{|c|c|}
\hline Parameter & Estimate \\
\hline Intercept & 0.9789 \\
\hline Id & 0.0001 \\
\hline Amount & $-0.0019 * *$ \\
\hline Type $_{1}$ & $-0.1564 *$ \\
\hline Type $_{2}$ & $-0.2222 * *$ \\
\hline Type $_{3}$ & $-0.1863 *$ \\
\hline Type $_{4}$ & 0.0000 \\
\hline Sector $_{1}$ & $-0.1609 *$ \\
\hline Sector $_{2}$ & -0.0963 \\
\hline Sector $_{3}$ & $-0.1850^{*}$ \\
\hline Sector $_{5}$ & $-0.2729 * * *$ \\
\hline Sector $_{6}$ & -0.1592 \\
\hline Sector $_{10}$ & $-0.3163 * * *$ \\
\hline Sector $_{12}$ & 0.0000 \\
\hline Project $_{1}$ & -0.0047 \\
\hline Project $_{2}$ & $0.3125 * *$ \\
\hline Project $_{3}$ & 0.0000 \\
\hline Metro & $0.0997 *$ \\
\hline $\begin{array}{l}* * * \text { significance at } 1 \% \\
* * \text { significance at } 5 \% \\
* \quad \text { significance at } 10 \%\end{array}$ & \\
\hline
\end{tabular}


Providing an explanation for why metropolitan firms are connected with higher participation rates can be accomplished from several points of view. It can be argued that these firms face increased competition, and thus, seek out ways to subsidize energy costs to gain a competitive advantage. On the other hand, the program itself may have inadvertently biased its focus on metropolitan areas due to their naturally larger population densities and business clustering. Finally, there is the possibility that part of this outcome can be attributed to the higher proportion of metropolitan firms responding.

\section{CONCLUSIONS AND POLICY IMPLICATIONS}

The objective of this paper was to better understand the regional and firm-level characteristics most strongly associated with participation in a public energy loan program. Findings indicate that requested amounts by firms at the time of inquiry move inversely with participation. The results also show that participation varies with the type of organization. When compared with a mixed group of non-profit, charitable, and government entities, the corporations, partnerships, and proprietorships were experiencing lower odds of participation. The sectors for which the energy loan was used for to improve energy conservation seem to influence participation. Participation drops significantly for a mixed selection of specific energy uses when compared with a base group that includes regulated dry cleaning firms. The results also show that "utility plant and distribution systems or water heating changes" are connected with higher participation rates, adding support to the claim that companies realizing large efficiency gains from internal energy improvements are participating in the program more often. Regional location seems to play a role in participation, as metropolitan firms are associated with higher rates of participation. In addition, since program inquiries move with interest rates, companies may have turned to the program during periods of rising interest rates to subsidize the costs of borrowing.

There is much to be gained from the results on how state agencies that manage the program carry out energy conservation strategy. The regulations placed on dry cleaning firms may have encouraged participation into the program. Firms may have found the program useful to offset cost increases when complying with the new regulations, and the program itself may have facilitated this process. However, accepting regulations as policy tools to motivate energy conservation among firms overlooks the private market's ability to produce efficient commercial energy use, as evidenced in the connection between inquiries and market interest rates.

Participation seems to rise significantly for those companies realizing the largest returns from the smallest changes. Although this is certainly an efficient outcome, attributing this result to that of the firms seeking out the program or the program seeking out the firms becomes increasingly difficult. It follows that a public program might maximize its effectiveness soliciting just those sectors realizing the greatest returns from the program rather than a blanket, marketing strategy.

The value of the program as an educational resource cannot be discounted. If an energy changing technology is already considered a positive net present value project, the program may then better serve as a way of providing information to firms to make this transition rather than a tool to subsidize financing for these changes. This is especially true for firms with high opportunity costs associated with searching for the appropriate energysaving technology. However, it is still true that targeting financial subsidies to those firms on the margin between participating and not participating will result in higher returns for an energy efficiency program that subsidizes the acquisition costs of such technologies.

The steady decline of inquiries over the years may signal that private market solutions are better at accommodating firm-level energy conservation projects. Inquiries generally moved with interest rates during the study period (with the exception of the later part of the study period) suggesting the possibility that financing for such projects need not be subsidized by the public sector when low-cost financing are available from the capital market. Figure 2 is possible evidence that the decision to investigate energy changes is still an investment choice where firms weigh the discounted present value of the benefits to the costs.

Metropolitan firms are connected with higher rates of participation, suggesting that competition may play a role as firms seek out ways to subsidize energy costs to gain a competitive advantage. Further investigation will 
examine whether other factors, such as regional differences in the prices of energy and the types of firms operating there, may be driving variation in participation across metropolitan and non-metropolitan firms.

This paper attempts to shed light on the factors most associated with a firm's decision to adopt an energysaving change. However, the administrators of a public program show signs of driving the winds of the change. This is evidenced in the mission statement of the program that requires firms, after receiving a free energy audit, to make the energy changes recommended by the program's administrators. Therefore, isolating the link between participation and industry trends remains a significant challenge as the program's motivations may also factor in, as participation rates may not fully reflect just a firm's willingness to do the program.

As an extension of this paper, the time-dependent aspect of the energy program should be examined more closely. Historical data, especially when dealing with movements in energy prices, can be subject to changing influences. Slight variation in the program's awareness or shifts over time in business activity within the state may impact participation. Also, the regional influence on participation should be investigated in more detail. For instance, was the absence of a significant regional effect in the model attributable to an unusually low representation of rural firms in the study? As DeCanio and Watkins (1998) find, EPA regional classifications do influence the choice to join a program. A more detailed examination will shed light on how firms, subject to varying degrees of regulatory actions based on their industry-type or regional location, behave towards the public energy loan program. Additionally, a few factors that may play a role in participation, such as the age and size of the companies, were not included in the econometric model. This is mainly due to the lack of sufficient and reliable data for these areas.

This paper provides valuable insight into the private-public dynamic that exists in energy conservation. There are two sides to this story, the private-market motivations cannot be exactly separated from those that are public. Hopefully, policymakers involved in these programs will make use of the findings in designing well targeted, energy efficiency initiatives. Scarce public resources used for such programs would generate higher returns if firms facing higher costs in acquiring energy efficiency information as well as financial capital constraints, are targeted specifically.

\section{AUTHOR INFORMATION}

Ferdinand DiFurio is an Assistant Professor at Tennessee Tech University. His areas of interest are business survival, regional economics, energy, and Econometrics. He has a $\mathrm{PhD}$ from Clemson University in Applied Economics.

Ferdinand Vinuya is an Energy Economist with the World Bank. He has a PhD from Clemson University in Applied Economics.

\section{REFERENCES}

1. 2005-2006 Annual Report. Tennessee Department of Economic and Community Development, Energy Division.

2. Allison, Paul D. Logistic Regression Using the SAS System: Theory and Application. SAS Institute Inc., Cary, NC, USA. 1999.

3. Annual Energy Outlook, 2007 (AEO). Energy Information Administration. Official Energy Statistics from the U.S. Government. Department of Energy. http://www.eia.doe.gov/oiaf/aeo/index.html

4. Baldwin, John and Zhengxi Lin. Impediments to Advanced Technology Adoption for Canadian Manufacturers. Statistics Canada, Research Paper Series, August 2001.

5. Carrao, C. and D. Siniscalco (1992) "Envionmental Innovation Policy and International Competition." Environmental and Resource Economics 2 183-200.

6. DeCanio, Stephen J. and William E. Watkins. Investment in Energy Efficiency: Do the Characteristics of Firms Matter? The Review of Economics and Statistics, v. 80, pp. 95-107, February 1998.

7. de Groot, Henri L.F. de, Erik T. Verhoef, and Peter Nijkamp. Energy Saving by Firms: Decision-Making, Barriers and Policies. Energy Economics. 23 717-740. 2001. 
8. Gielecki, Mark, Fred Mayes and Lawrence Prete. Incentives, Mandates, and Government Programs for Promoting Renewable Energy. Energy Information Administration (EIA). 2001.

9. Gouchoe, Susan, Valerie Everette, Rusty Haynes. State Incentives for Renewable Energy: Case Studies on Program Effectiveness. North Carolina Solar Center, North Carolina State University.

10. Gouchoe, Susan, Valerie Everette, Rusty Haynes. Case Studies on the Effectiveness of State Financial Incentives for Renewable Energy. National Renewable Energy Laboratory. September 2002.

11. Lancaster, Richard R. and Mark J. Berndt. Alternative Energy Development in the USA: The Effectiveness of State Government Incentives. Energy Policy. Vol. 12, Issue 4, pp. 170-179, June 1984.

12. NCSC. North Carolina Solar Center. Solar Center Information, State Energy Office, North Carolina Department of Administration, NCSU, Raleigh, NC 27695.

13. Pizer, William A., Winston Harrington, Raymond J. Kopp, Richard D. Morgenstern and Jhih-Shyang Shih. Technology Adoption and Aggregate Energy Efficiency. Discussion Paper, Resources for the Future. 2002.

14. Randolph, John. Energy Conservation Programmes: A Review of State Incentives in the USA. Energy Policy. Vol. 12, Issue 4, pp. 425-438, December 1984.

15. Tennessee Department of Economic and Community Development (DECD). Report by the Governor's Interagency Energy Policy Work Group in Response to Executive Order 27. January 2002.

16. U.S. Department of Energy (DOE). Energy Efficiency and Renewable Energy. May 2006. http://www.eere.energy.gov/afdc/progs/state_summary.cgi?afdc/TN

17. U.S. Department of Energy (DOE). Energy Consumption by Sector, Ranked by State, 2003. http://www.eia.doe.gov/emcu/states/sep_sum/plain_html/rank_use.html

18. Verhoef, Erik and Peter Nijkamp. The Adoption of Energy Efficient Enhancing Technologies: Market Performance and Policy Stategies in Case of Heterogeneous Firms. This article was in Economic Modeling 20 839-871. 2003.

\footnotetext{
${ }^{\mathrm{i}}$ AEO, 2007. Energy Information Administration. http://www.eia.doe.gov/oiaf/aeo/index.html

${ }^{i i}$ AEO, 2007. Energy Information Administration. http://www.eia.doe.gov/oiaf/aeo/index.html, Commercial: TN, 8.09; U.S., 9.11. Industrial: TN, 5.29; U.S., 5.97

iii The Environmental Protection Agency's voluntary Green Lights program

${ }^{\text {iv }}$ Participation implies successful completion of the program. As a result, interpretation of a "participation" represents a firm's willingness (through the initial inquiry) and ability (as established by an approval) to make an energy change.

${ }^{\mathrm{v}}$ For the logistic model, only 355 observations were used.

vi This finding is based on the county's rural urban continuum code classification in 1993 and 2003 provided by the Economic Research Service.

vii The water heating types are not identical to the heating and cooling systems in category 3 , so an effort is made here to distinguish them; The utility plant and distribution system modifications can be better described as motor system processes that operate on a close tolerance. Efficient outcomes are necessary, and changes made to these processes make a big difference on energy input demand.

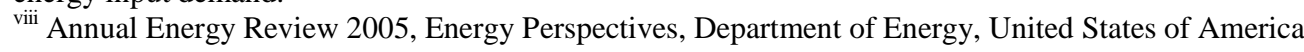

${ }^{\text {ix }}$ The following calculation was made: $\left(e^{(0.0997)}-1\right) * 100$.
} 
NOTES 